\title{
miRNA-302e attenuates inflammation in infantile pneumonia though the RelA/BRD4/NF-кB signaling pathway
}

\author{
SHAOXIA LI ${ }^{1 *}$, WENWEN CUI ${ }^{1 *}$, QING SONG ${ }^{1}$, YUFEI ZHOU ${ }^{2}$ and JINGTAO LI ${ }^{3}$ \\ Departments of ${ }^{1}$ Pediatrics and ${ }^{2}$ Thoracic Surgery, The People's Hospital of Dongying, Dongying, Shandong 257091; \\ ${ }^{3}$ Department of Surgery, The Second People's Hospital of Laiyang, Yantai, Shandong 265200, P.R. China
}

Received July 30, 2018; Accepted April 12, 2019

DOI: $10.3892 /$ ijmm.2019.4194

\begin{abstract}
In the present study, the main focus was investigating the role of microRNA (miRNA)-302e in infantile pneumonia (IP) and exploring the potential protective mechanisms. Briefly, the expression of miRNA-302e was reduced in a mouse model of IP. In addition, the administration of anti-miRNA-302e increased inflammation and induced the protein expression of RelA, bromodomain-containing protein 4 (BRD4) and nuclear factor (NF)- $\mathrm{kB}$ in the in vitro model of IP. In contrast, over-expression of miRNA-302e reduced inflammation and suppressed the protein expression of RelA, BRD4 and NF- $\mathrm{KB}$ in an in vitro model of IP. Small interfering (si)-RelA attenuated the effects of miRNA-302e on inflammation in an in vitro model of IP. Consistently, si-BRD4 or si-NF- $\mathrm{kB}$ attenuated the effects of miRNA-302e on inflammation in an in vitro model of IP. Taken together, the results of the present study demonstrated that miRNA-302e attenuated inflammation in IP through the RelA/ BRD4/ NF- $\mathrm{kB}$ signaling pathway.
\end{abstract}

\section{Introduction}

Infantile pneumonia (IP) is pulmonary infection induced by mycoplasma pneumoniae, which is also called primary atypical pneumonia that is commonly seen in infants, school-age children and adolescents (1). In recent years, mycoplasma pneumoniae pneumonia (MPP) accounts for a gradually increasing proportion in community acquired pneumonia (CAP), which may occur all year round and is more frequently seen in winter and spring. Its incubation period is as long as 2-3 weeks and can spread through droplet transmission (2). Typically, most cases have good a prognosis, but this disease is highly recurrent and

Correspondence to: Dr Shaoxia Li, Department of Pediatrics, The People's Hospital of Dongying, 317 Nanyi Road, Dongying, Shandong 257091, P.R. China

E-mail: iwgksq3820000@126.com

*Contributed equally

Key words: miRNA-302e, RelA, bromodomain-containing protein 4, nuclear factor- $\kappa \mathrm{B}$, infantile pneumonia severe lung lesion may develop in certain rare cases (2). In addition, it may be accompanied by severe complications, including encephalitis, myelitis and nephritis (2). Lipopolysaccharide (LPS)-induced A549 cells is a common IP model used to research pulmonary inflammation and injury (3-5).

Inflammation is the defense reaction to the damage of living tissues in the vascular system, and inflammation can eliminate hazardous substances that enter the body, but it may also induce injury to the body (6). IP has become a common and frequently-occurring disease in children, which has attracted increasing attention due to its long course, severe symptoms and possibility of inducing multiple extrapulmonary complications (7). IP is known to be caused by mycoplasma infection; nonetheless, the pathogenesis of IP-induced inflammatory response remains incompletely understood (6). It is currently suggested that MPP is a systemic disease involving the immune system and cytokines serve a leading role in IP-induced immune injury, which is supported in a number of recent studies $(7,8)$. Particularly, cytokines and inflammatory mediators, including tumor necrosis factor (TNF)- $\alpha$ and interleukin (IL)-6, are directly involved in this process. TNF- $\alpha$ is a dominant cytokine produced by monocytes and macrophages and is an inflammatory mediator with important bioactivity (8). It can induce neutrophil chemotaxis, local infiltration, phagocytosis and the killing of pathogens, therefore initiating the inflammatory response (9). IL-6 is produced by monocytes and macrophages and lymphocytes spontaneously or under the stimulation of various factors, and it is an important cytokine in the inflammatory response and the vital mediator synthesized during the acute phase (9).

MicroRNA (miRNA) is non-coding RNA that serves a post-transcriptional regulatory role in gene transcription and translation (10). It can regulate post-transcriptional expression of target genes, therefore serving a vital role in biological development, reproduction, cell differentiation, apoptosis and pathogenesis. A number of diseases are recognized to be associated with the inflammatory response; therefore, it is of crucial importance to study the pathogenesis of inflammation (11). Recent studies identified that miRNA can regulate multiple body activities, including regulation of inflammatory responses and multiple miRNAs have been demonstrated to be involved in regulating the inflammatory response and inflammatory diseases $(3,11)$.

RelA is an important member of the NF-kB family, which can regulate target genes to participate in vital life activities, including cell proliferation, transformation, apoptosis, 
inflammation and immune response (12). In addition, these functions are regulated by multiple post-translational modifications, like phosphorylation, acetylation and methylation (12).

Nuclear factor $\kappa \mathrm{B}(\mathrm{NF}-\kappa \mathrm{B})$, first discovered in $\mathrm{B}$ cells in 1986 , is a nuclear protein factor that can specifically bind with immunoglobulin ( $\mathrm{Ig}) \mathrm{G} \kappa$ light chain gene enhancer $\kappa \mathrm{B}$ sequence (GGGACTTTC) (13). It is extensively distributed in eukaryocytes and participates in vital pathophysiological processes, like cell proliferation, transformation, apoptosis, inflammation and immune responses. Therefore, it has attracted extensive attention from scholars. At present, there are 5 members in the NF- $\kappa \mathrm{B}$ family, including RelA, RelB,

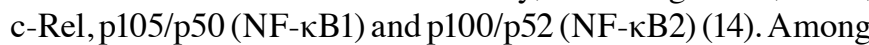
them, RelA can regulate the transcription activity of multiple downstream target genes due to its special transactivation domain and participate in multiple vital cellular activities, therefore it has become the research focus of the NF- $\kappa \mathrm{B}$ family (14). Xiao et al (15) and Peng et al (16), demonstrated that the miRNA-302 cluster downregulates the enterovirus 71-induced innate immune response and inflammation. The present study investigated the role of miRNA-302e in IP and the potential protective mechanisms.

\section{Materials and methods}

IP model. A total of 1 week old C57BL/6 mice (male, 4-5 g, $\mathrm{n}=20$ ) mice was purchased from the Animal laboratory of Shandong University (Shandong, China). C57BL/6 mice were randomly assigned to one of two groups: Sham $(n=10)$ and IP group $(n=10)$. C57BL/6 mice of the sham group were injected with normal saline for $8 \mathrm{~h}$ under $50 \mathrm{mg} / \mathrm{kg}$ pentobarbital sodium pentobarbital sodium. C57BL/6 mice with IP were injected with $2 \mathrm{mg} / \mathrm{kg}$ of LPS (Sigma-Aldrich Merck KGaA) under $50 \mathrm{mg} / \mathrm{kg}$ pentobarbital sodium (intraperitoneal) $(17,18)$. A total of $8 \mathrm{~h}$ later, peripheral blood $(100 \mu \mathrm{l})$ was collected from a leg vein under $50 \mathrm{mg} / \mathrm{kg}$ pentobarbital sodium and serum was centrifuged at $1,000 \mathrm{xg}$ for $10 \mathrm{~min}$ at $4^{\circ} \mathrm{C}$. Mice were sacrificed using decollation under $50 \mathrm{mg} / \mathrm{kg}$ pentobarbital sodium following induction for IP.

Lung tissue samples were collected and fixed with $4 \%$ paraformaldehyde for $24 \mathrm{~h}$ at room temperature or preserved at $-80^{\circ} \mathrm{C}$. All experiments have been approved by the Ethics Committee of The People's Hospital of Dongying (Dongying, China).

Hematoxylin and eosin $(H \& E)$ staining. Lung tissue samples fixed with paraformaldehyde were paraffin-embedded and stored at $4^{\circ} \mathrm{C}$. The lung tissue samples were cut into $10 \mu \mathrm{m}$ sections using a paraffin slicing machine (RM2235; Leica Microsystems GmbH, Wetzlar, Germany), stained with hematoxylin and eosin for $10 \mathrm{~min}$ at room temperature and observed under light microscopy (magnification, x100; BH3-MJL; Olympus Corporation, Tokyo, Japan).

ELISA assay kits. Serum samples and transfected cell samples after induction of infantile pneumonia were collected at $1,000 \times \mathrm{g}$ for $10 \mathrm{~min}$ at $4^{\circ} \mathrm{C}$. Serum samples were used to measure TNF- $\alpha$, IL-1 $\beta$, IL-6 and IL-18 levels using ELISA kits. Cell samples was lysed using radioimmunoprecipitation assay (RIPA) buffer (Beyotime Institute of Biotechnology, Haimen, China) and used to measure TNF- $\alpha$ (cat. no. H052),
IL-1 $\beta$ (cat. no. H002), IL-6 (cat. no. H007) and IL-18 (cat. no. H015) levels using ELISA kits (Nanjing Jiancheng Institute of Biological Engineering). The optical density value was detected using a microplate reader (BioTek Instruments, Inc., Winooski, VT, USA) at $450 \mathrm{~nm}$.

Immunofluorescent staining. Cells were fixed with $4 \%$ paraformaldehyde for at room temperature $15 \mathrm{~min}$, permeabilized using $0.1 \%$ Triton X-100 for 15 min and blocked with $5 \%$ bovine serum albumin (BSA; Beyotime Institute of Biotechnology) in PBS for $1 \mathrm{~h}$ at $37^{\circ} \mathrm{C}$. Cells were labeled with rabbit-anti-RelA (1:100) antibody (cat. no. ab76228; Abcam Cambridge, UK) at $4^{\circ} \mathrm{C}$ overnight. Cells was washed three times with PBS and incubated with goat anti-rabbit IgG-CFL 555 antibody (cat. no. sc-362272; 1:100; Santa Cruz Biotechnology, Inc., Dallas, TX, USA) for $1 \mathrm{~h}$ at room temperature. Cells were stained with DAPI for $15 \mathrm{~min}$ and washed with PBS for $15 \mathrm{~min}$. Cell images were obtained using a Zeiss Axioplan 2 fluorescent microscope (Carl Zeiss AG, Oberkochen, Germany).

Reverse transcription-quantitative polymerase chain reaction (RT-qPCR) and Gene microarray hybridization. Total RNA was extracted from lung tissue samples or cell using TRIzol reagent (Invitrogen; Thermo Fisher Scientific, Inc., Waltham, MA, USA) and cDNA production was carried out using a RevertAid First Strand cDNA Synthesis kit (Thermo Fisher Scientific, Inc.) at $37^{\circ} \mathrm{C}$ for $60 \mathrm{~min}$ and $82^{\circ} \mathrm{C}$ for $10 \mathrm{sec}$. qPCR was performed with Power SYBR-Green Master Mix (Toyobo Life Science, Osaka, Japan) on a Prism 7000 Real-Time PCR System (Applied Biosystems; Thermo Fisher Scientific, Inc.). Relative gene expression was calculated with the $2^{-\Delta \Delta \mathrm{Cq}}$ method. The PCR cycling conditions were as follows: $94^{\circ} \mathrm{C}$ pre-degeneration for $5 \mathrm{~min}, 94^{\circ} \mathrm{C}$ degeneration for $30 \mathrm{sec}, 60^{\circ} \mathrm{C}$ annealing for $30 \mathrm{sec}, 72^{\circ} \mathrm{C}$ extension for $1 \mathrm{~min}$, for 40 cycles. miRNA-302e forward, 5'-TTGGGTAAGTGCTTCCATGA-3' and reverse, 5'-GTAATAGCACCTACCTTATAGA-3'; U6 forward, 5'-GCT TCGGCAGCACATATACTAAAAT-3', 5'-CTTCGGCAGCAC ATA 5-CCGCTTCACGAATTTGCGTGTCAT-3'. The relative expression was analyzed using the $2^{-\Delta \Delta \mathrm{Cq}}$ method (19).

Total RNA was labelled using Cyanine-5-CTP and hybridized to the SurePrint and G3 Mouse Whole Genome GE 8x60 K Microarray G4852A platform (NEL474001EA; PerkinElmer, Inc., Waltham, MA, USA) with an equimolar concentration of Cyanine-3-CTP-labelled universal mouse (Stratagene; Agilent Technologies, Inc., Santa Clara, CA, USA). Images were quantified and feature-extracted using Agilent Feature Extraction Software (v.A.10.7.3.1; Agilent Technologies, Inc.).

In vitro model. A549 cell was purchased from the Type Culture Collection of the Chinese Academy of Sciences (Shanghai, China) and was maintained in Dulbecco's modified Eagle's medium (Gibco; Thermo Fisher Scientific, Inc.) supplemented with $10 \%$ fetal bovine serum (Gibco; Thermo Fisher Scientific, Inc.) in a humidified incubator at $37^{\circ} \mathrm{C}$ and $5 \% \mathrm{CO}_{2}$. Small interfering (si)-RelA (cat. no. s11917; Ambion; Thermo Fisher Scientific, Inc.), si-BRD4 (cat. no. sc-43639) and si-NF-кB (cat. no. sc-44212) were purchased from Santa Cruz Biotechnology, Inc. miRNA-302e (5'-UAAGUGCUUCCAUGUUUUGG UGA-3'), anti-miRNA-302e (5'-AUUCACGAAGGUACA AAACCACU-3') and negative control mimics (5'-UCACAA 
A

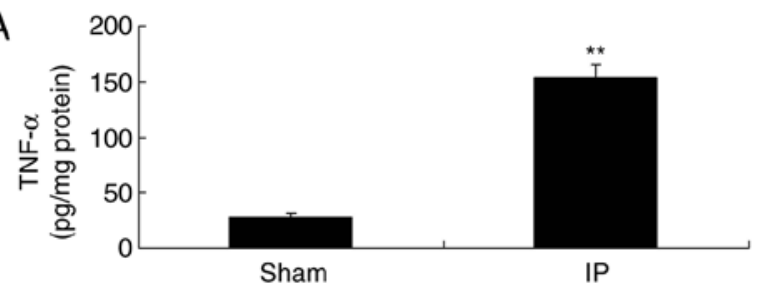

C

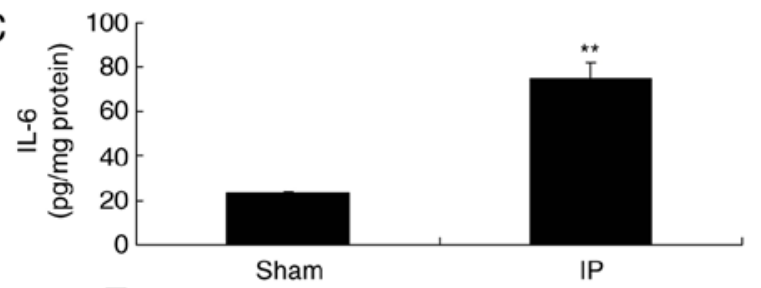

$\mathrm{E}$

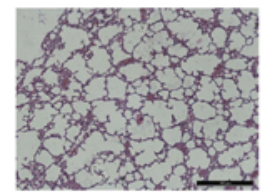

G

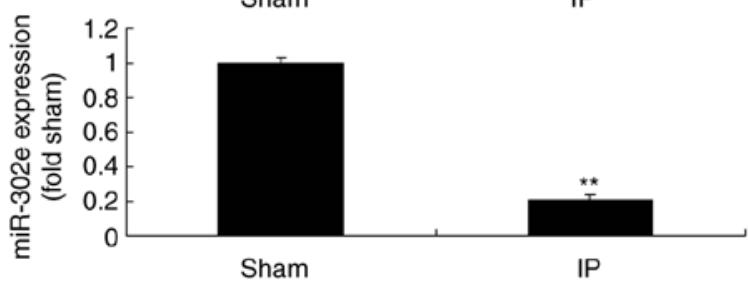

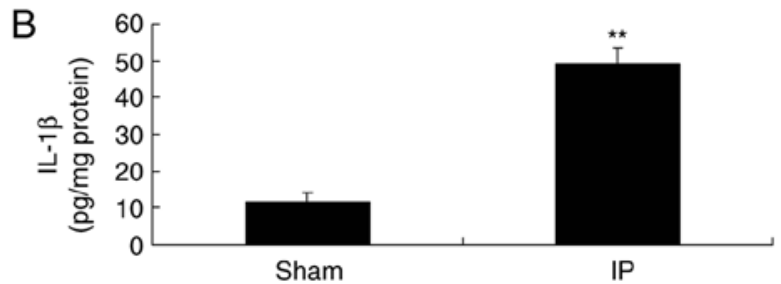
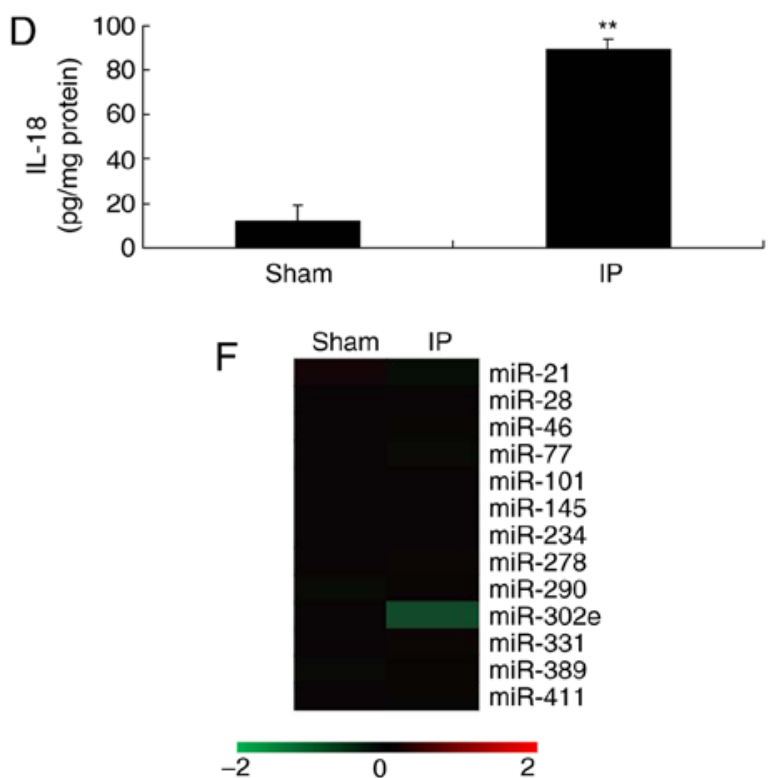

Figure 1. miRNA-302e expression in IP model mice. (A) TNF- $\alpha$, (B) IL-1 $\beta$, (C) IL-6 and (D) IL-18 levels, lung tissue using (E) hematoxylin an eosin assay, (F) gene chip for miR expression and $(\mathrm{G})$ quantitative polymerase chain reaction for miRNA-302e expression in a mouse IP model. ${ }^{* *} \mathrm{P}<0.01$ vs. the sham control group. Sham, sham control group; IP, infantile pneumonia; IL, interleukin; TNF, tumor necrosis factor; miR, microRNA.

CCUCCUAGAAAGAGUAGA-3') were purchased from Sangon Biotech (Shanghai) Co., Ltd. (Shanghai, China). A total of $100 \mathrm{ng}$ of si-RelA (cat. no. sc-61876; Santa Cruz Biotechnology, Inc.), 100 ng of si-BRD4 (cat. no. sc-43639; Santa Cruz Biotechnology, Inc.), $100 \mathrm{ng}$ of si-NF- $\kappa \mathrm{B}$ (cat. no. sc-29410; Santa Cruz Biotechnology, Inc.), 100 ng of miRNA-302e, $100 \mathrm{ng}$ of anti-miRNA-302e and $100 \mathrm{ng}$ of negative mimics were transfected into cells $\left(1 \times 10^{5}\right.$ cell $\left./ \mathrm{ml}\right)$ using Lipofectamine 2000 (Thermo Fisher Scientific, Inc.) for $48 \mathrm{~h}$. Following $48 \mathrm{~h}$, cells were treated with $100 \mathrm{ng} / \mathrm{ml}$ of LPS for $6 \mathrm{~h}(3,6,17)$ and used for western blotting or RT-qPCR.

Luciferase reporter assay. pGL3-RelA-3' untranslated region (UTR) plasmids were obtained from Shanghai GeneChem Co., Ltd. (Shanghai, China). pGL3-RelA-3'UTR plasmid and anti-miRNA-302e were co-transfected into cells using Lipofectamine-2000 for $48 \mathrm{~h}$. Reporter activity was quantified at $48 \mathrm{~h}$ following transfection using a Dual-Luciferase Reporter Assay kit (Beyotime Institute of Biotechnology). Readings were taken with a Lumat LB 9507 instrument (Berthold Technologies, Bad Wildbad, Germany). pRL-TK (Promega Corporation, Madison, WI, USA) was transfected as a normalization control. Comparison with Renilla luciferase activity was performed.

Western blot analysis. Total protein extracts were obtained from transfected cells at $48 \mathrm{~h}$ using cold RIPA buffer (Beyotime Institute of Biotechnology) and protein concentration was measured using bicinchoninic acid assay (Beyotime
Institute of Biotechnology). Total protein (50 $\mu \mathrm{g})$ was loaded on $10 \%$ SDS-PAGE gels, electrophoresed and transferred onto a polyvinylidene difluoride membrane. Membranes were blocked with $5 \%$ non-fat milk in TBS with $0.1 \%$ Tween 20 for $1 \mathrm{~h}$ at $37^{\circ} \mathrm{C}$ and probed for RelA (1:1,000; cat. no. sc-81622), BRD4 (1:1,000; cat. no. sc-518021), NF- $\mathrm{B}(1: 1,000$; cat. no. sc-71675) and GAPDH (1:5,000; cat. no. sc-293335) overnight at $4^{\circ} \mathrm{C}$. The membranes were incubated at room temperature for $1 \mathrm{~h}$ with appropriate horseradish peroxidase (HRP)-conjugated secondary antibodies (cat. no. sc-2004; 1:5,000; Santa Cruz Biotechnology, Inc., Dallas, TX, USA) visualized with enhanced chemiluminescence (Beyotime Institute of Biotechnology) and analyzed using Image Lab 3.0 (Bio-Rad Laboratories, Inc., Hercules, CA, USA).

Statistical analysis. All data are presented as the mean \pm standard deviation ( $\mathrm{n}=3$ ) using SPSS 17.0 (SPSS, Inc., Chicago, IL, USA). Student's t-test or one-way analysis of variance and Tukey's post-hoc test were used carried out statistical analysis. $\mathrm{P}<0.05$ was considered to indicate a statically significant difference.

\section{Results}

Expression of miRNA-302e in mouse model of IP. To investigate the roles of miRNAs in a mouse model of IP, the changes of miRNAs in were analyzed. The levels of TNF- $\alpha$, IL-1 $\beta$, IL-6 and IL-18 were significantly increased in the mouse model of IP compared with the sham mice $(\mathrm{P}<0.01$; Fig. 1A-D). 
A

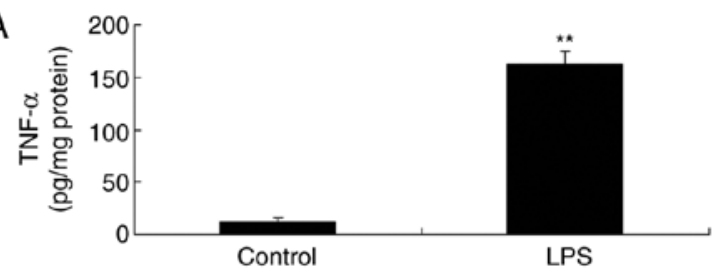

C

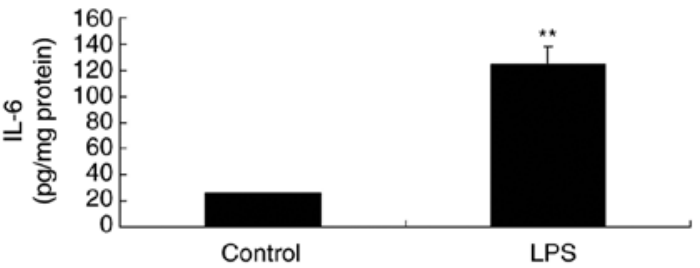

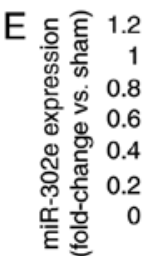

Control

LPS

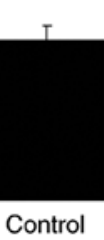

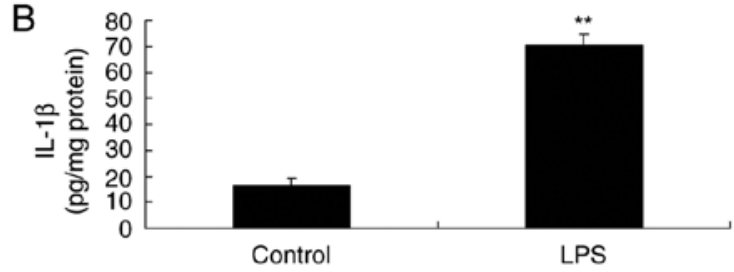

D

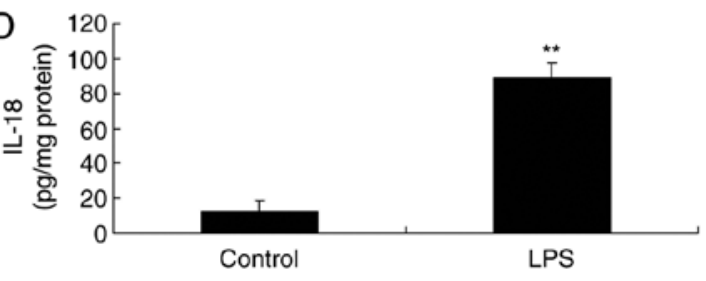

Figure 2. miRNA-302e expression in an in vitro model of IP. (A) TNF- $\alpha$, (B) IL-1 $\beta$, (C) IL-6 and (D) IL-18 levels and (E) quantitative polymerase chain reaction for miRNA-302e expression in a mouse IP model. Control, control group; LPS, $100 \mathrm{ng} / \mathrm{ml}$ of LPS group. ${ }^{* *} \mathrm{P}<0.01 \mathrm{vs.} \mathrm{the} \mathrm{control} \mathrm{group.} \mathrm{IL,} \mathrm{interleukin;}$ LPS, lipopolysaccharide; miRNA, microRNA; TNF, tumor necrosis factor; IP, infantile pneumonia.
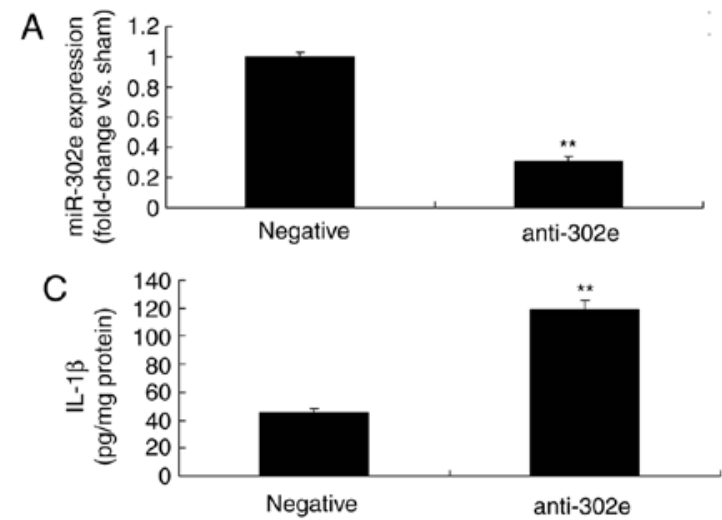

E

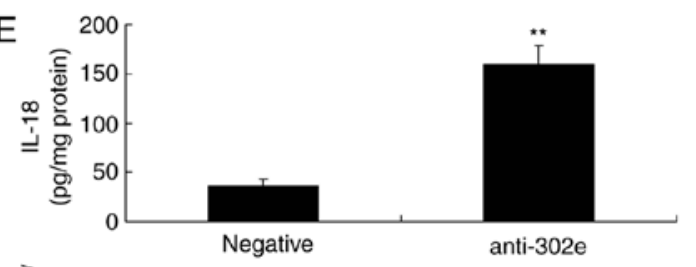

$\mathrm{G}$

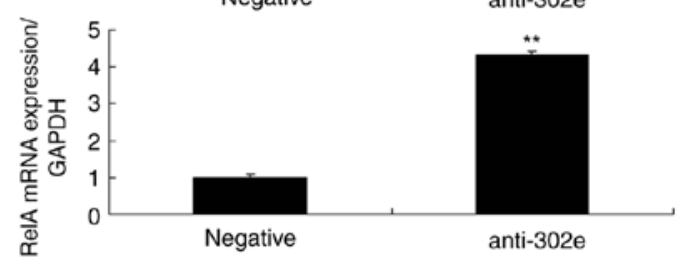

$\mathrm{H}$

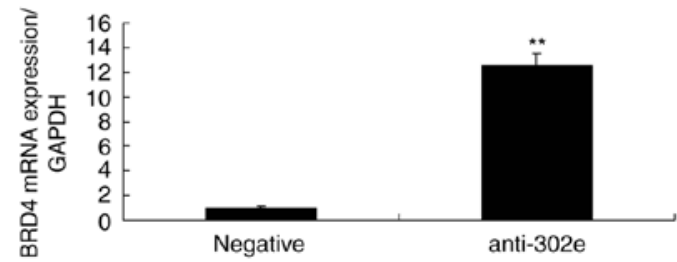

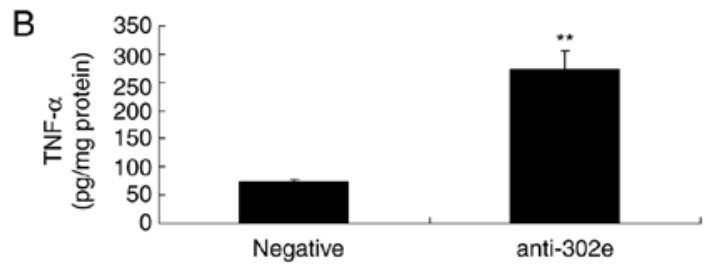

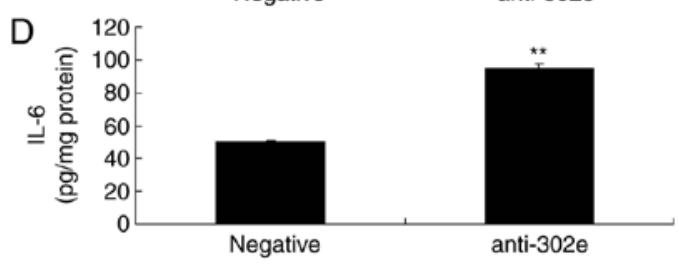

F Negative anti-302e
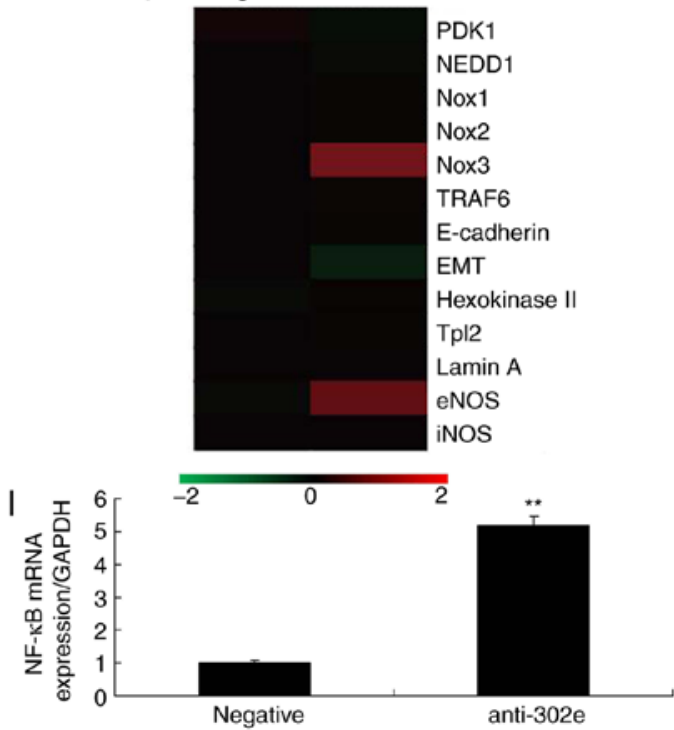

Figure 3. Downregulation of miRNA-302a regulates inflammation in an in vitro model of infantile pneumonia. (A) quantitative polymerase chain reaction for miRNA-302e expression, (B) TNF- $\alpha$, (C) IL-1 $\beta$, (D) IL-6 and (E) IL-18 levels, (F) gene chip, qPCR for (G) RelA, (H) BRD4 and (I) NF- $\kappa$ B expression. ${ }^{* *} \mathrm{P}<0.01$ vs. the negative control group. Negative, negative control group; anti-302a, downregulation of miRNA-302a group; qPCR, quantitative polymerase chain reaction; TNF, tumor necrosis factor; IL, interleukin; NF, nuclear factor; BRD4, bromodomain-containing protein 4; miRNA, microRNA. 


\section{A RelA---AAGCACUUA--- miRNA-302e---UUCGUGAAU}
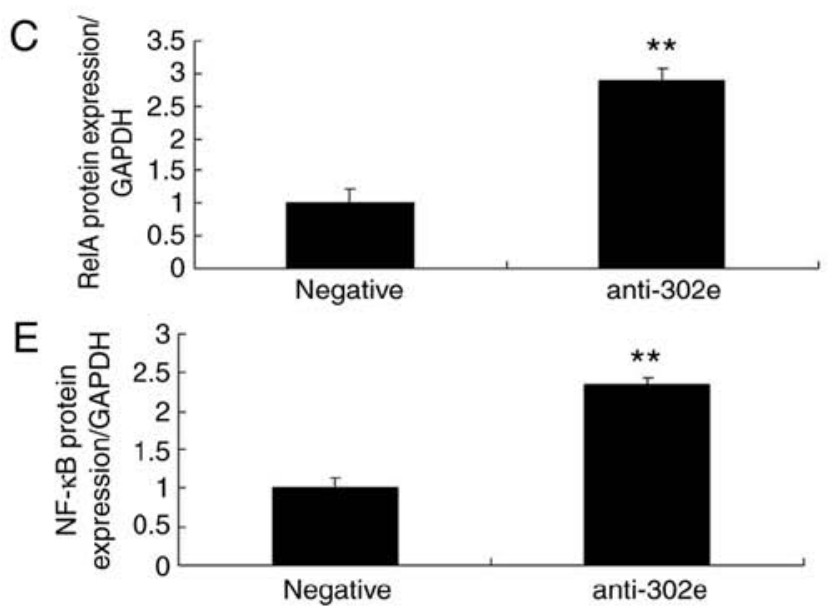
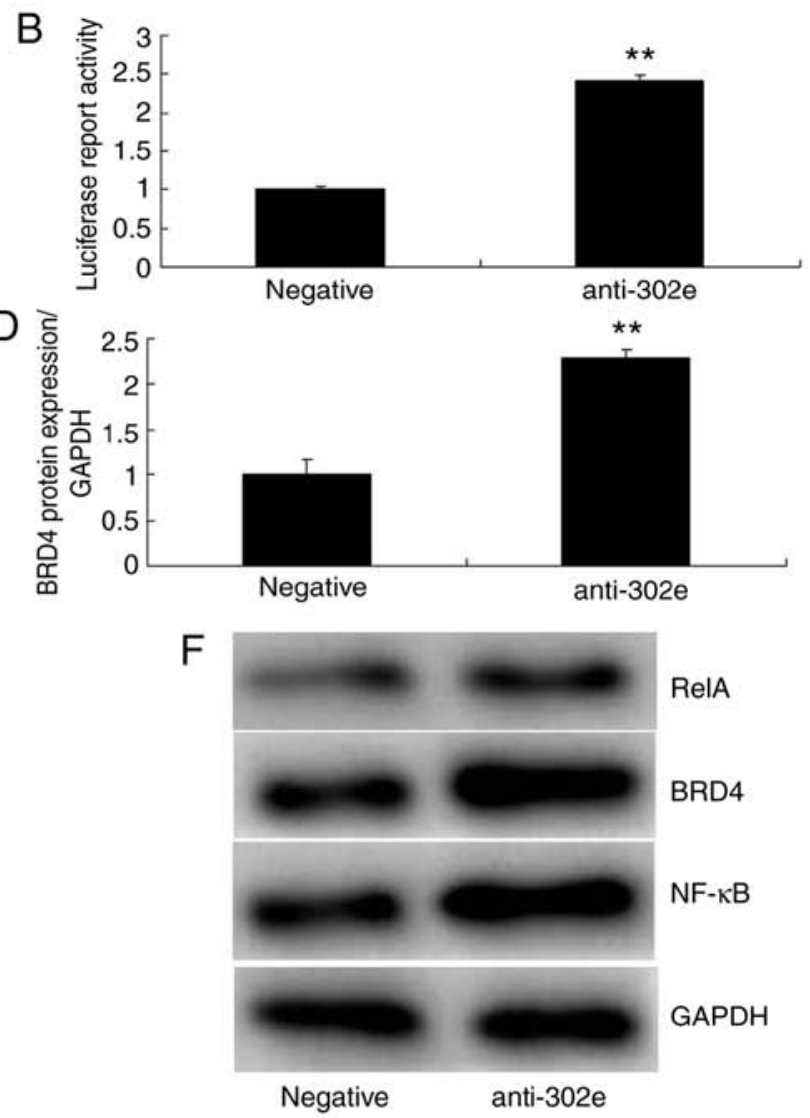

Merge
G

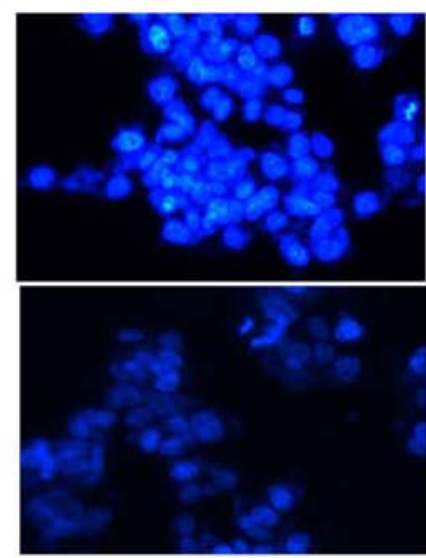

RelA

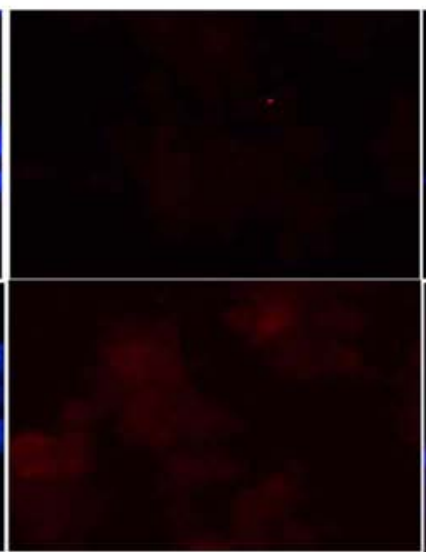

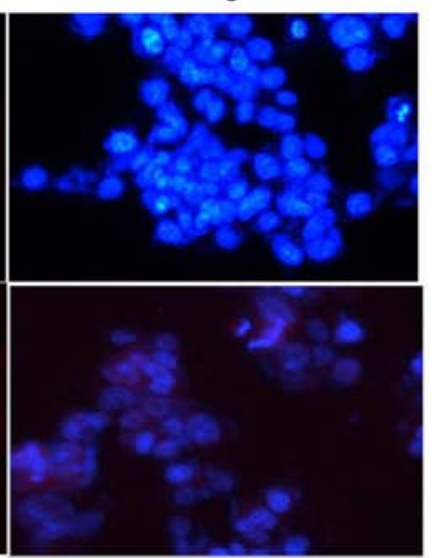

Negative

anti-302e

Figure 4. Downregulation of miRNA-302a regulates RelA/BRD4/NF- $\mathrm{B}$ signaling pathway in an in vitro model of infantile pneumonia. (A) miRNA-302a matches to the sequence in the 3-UTR of RelA, (B) luciferase reporter, (C) RelA, (D) BRD4 and (E) NF- $\kappa$ B protein expression by statistical analysis, and (F) western blotting analysis, (G) RelA protein expression by immunofluorescence. ${ }^{* *} \mathrm{P}<0.01$ vs. the negative control group. Negative, negative control group; anti-302a, downregulation of miRNA-302a group; NF, nuclear factor; BRD4, bromodomain-containing protein 4; miRNA, microRNA.

H\&E staining demonstrated that the pulmonary alveoli were shrunken in the mouse model of IP, in comparison to sham mice (Fig. 1E). These results of H\&E staining, TNF- $\alpha$, IL-1 $\beta$, IL-6 and IL-18 levels indicated that the in vivo model was successfully established. Moreover, the expression of miRNA-302e was significantly decreased in a mouse model of IP compared with the sham group $(\mathrm{P}<0.01$; Fig. 1F-G). Therefore, miRNA-302e may be involved in inflammation in IP.

Expression of miRNA-302e in an in vitro model of IP. Then, it was demonstrated that the levels of TNF- $\alpha$, IL-1 $\beta$, IL-6 and IL-18 were significantly promoted in LPS-induced A549 cells, compared with the control group ( $\mathrm{P}<0.01$; Fig. 2A-D). As expected, the expression of miRNA-302e was significantly decreased in the LPS-induced group compared with the control group $(\mathrm{P}<0.01$; Fig. $2 \mathrm{E})$. Therefore, these results demonstrated that miRNA-302e served a role in the inflammation of IP in vitro.

Downregulation of miRNA-302a regulates inflammation in an in vitro model of IP by the RelA/BRD4/NF- $\kappa B$ signaling pathway. In addition, the expression of miRNA-302e was significantly downregulated in in vitro model of IP $(\mathrm{P}<0.01$; Fig. 3A). The levels of TNF- $\alpha$, IL-1 $\beta$, IL- 6 and IL-18 were 

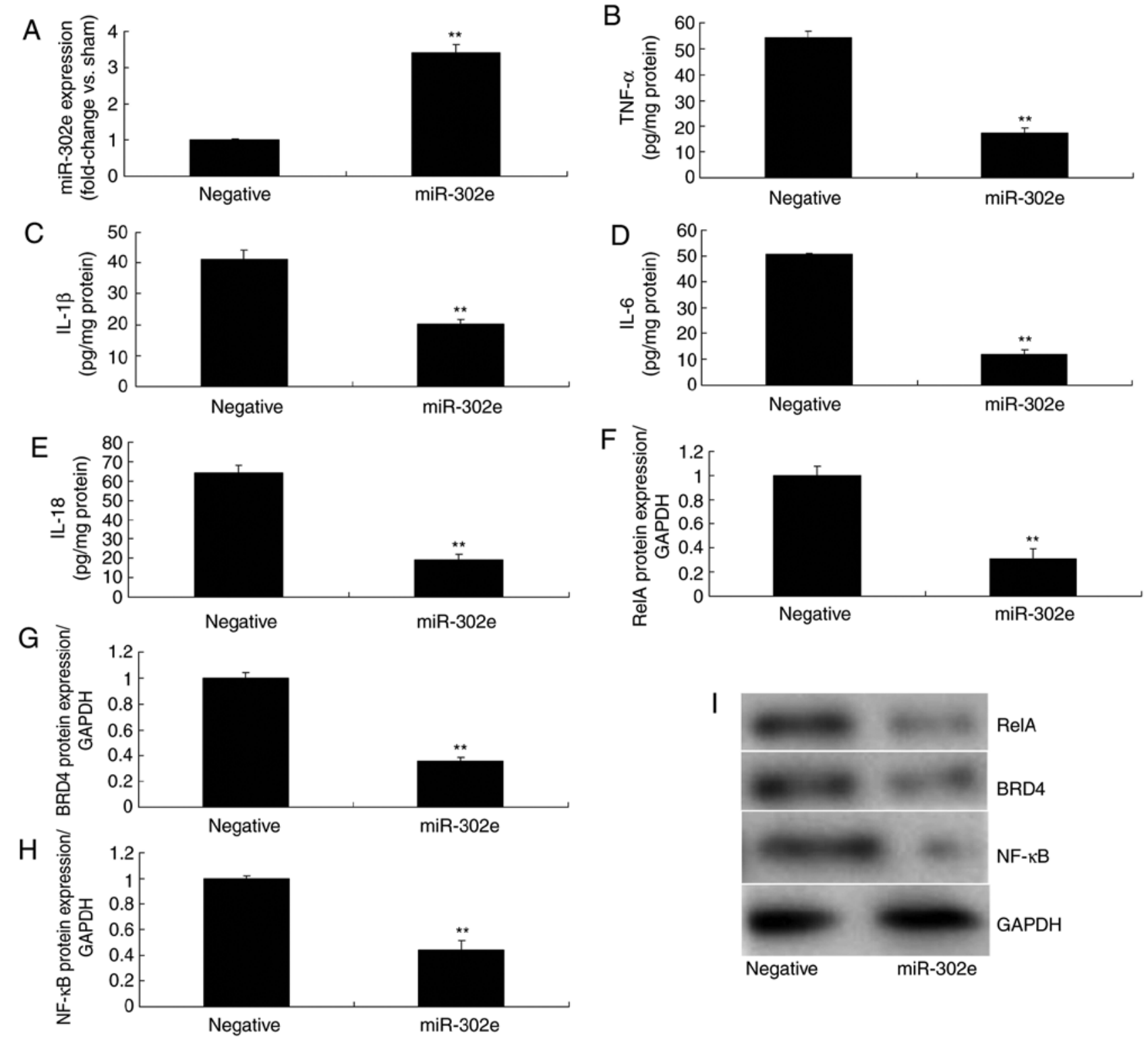

Figure 5. miRNA-302e regulates the RelA/ BRD4/ NF- $\mathrm{kB}$ signaling pathway in an in vitro model of infantile pneumonia. (A) quantitative polymerase chain reaction for miRNA-302e expression, (B) TNF- $\alpha$, (C) IL-1 $\beta$, (D) IL-6 and (E) IL-18, (F) RelA, (G) BRD4 and (H) NF- $\mathrm{kB}$ protein expression by statistical analysis, and (I) western blotting analysis. ${ }^{* *} \mathrm{P}<0.01$ vs. the negative control group. Negative, negative control group; miR-302a, upregulation of miRNA-302a group; TNF, tumor necrosis factor; IL, interleukin; NF, nuclear factor; BRD4, bromodomain-containing protein 4; miRNA, microRNA.

significantly increased in an in vitro model of IP by downregulation of miRNA-302a compared with the control group $(\mathrm{P}<0.01$; Fig. 3B-E). Then, a gene chip was utilized to analyze the expression of inflammatory signaling pathways, which revealed that the expression of RelA, BRD4 and $\mathrm{NF}-\kappa \mathrm{B}$ was significantly induced in the in vitro model of IP following downregulation of miRNA-302a, in comparison with the control group $(\mathrm{P}<0.01$; Fig. $3 \mathrm{~F}-\mathrm{I})$. As presented in Fig. 4A and B, the 3-UTR of RelA was complementary to the miRNA-302e seed sequence and luciferase activity levels also were increased in the in vitro model of IP following downregulation of miRNA-302a, compared with the negative group. The protein expression of RelA, BRD4 and $\mathrm{NF}-\kappa \mathrm{B}$ was induced in the in vitro model of IP by downregulation of miRNA-302a, in comparison to the negative group (Fig. 4C-F). IF demonstrated that the protein expression of RelA was increased in the in vitro model of IP by downregulation of miRNA-302a compared with the negative group (Fig. 4G). These data indicated that miRNA-302a regulated RelA expression in IP in vitro.

miRNA-302e regulates the RelA/BRD4/NF- $\kappa B$ signaling pathway in an in vitro model of IP. Next, the function and mechanism of miRNA-302e in IP was analyzed in vitro. MiRNA-302e mimics were used to significantly increase the expression of miRNA-302e in the in vitro model of IP, compared with the negative group $(\mathrm{P}<0.01$; Fig. 5A). The levels of TNF- $\alpha$, IL-1 $\beta$, IL- 6 and IL-18 were significantly reduced in the in vitro model of IP following over-expression of miRNA-302e, in comparison with the negative group $(\mathrm{P}<0.01$; Fig. 5B-E). Over-expression of miRNA-302e significantly suppressed the protein expression of RelA, BRD4 and NF- $\kappa \mathrm{B}$ in IP in vitro, compared with the negative group $(\mathrm{P}<0.01$; 

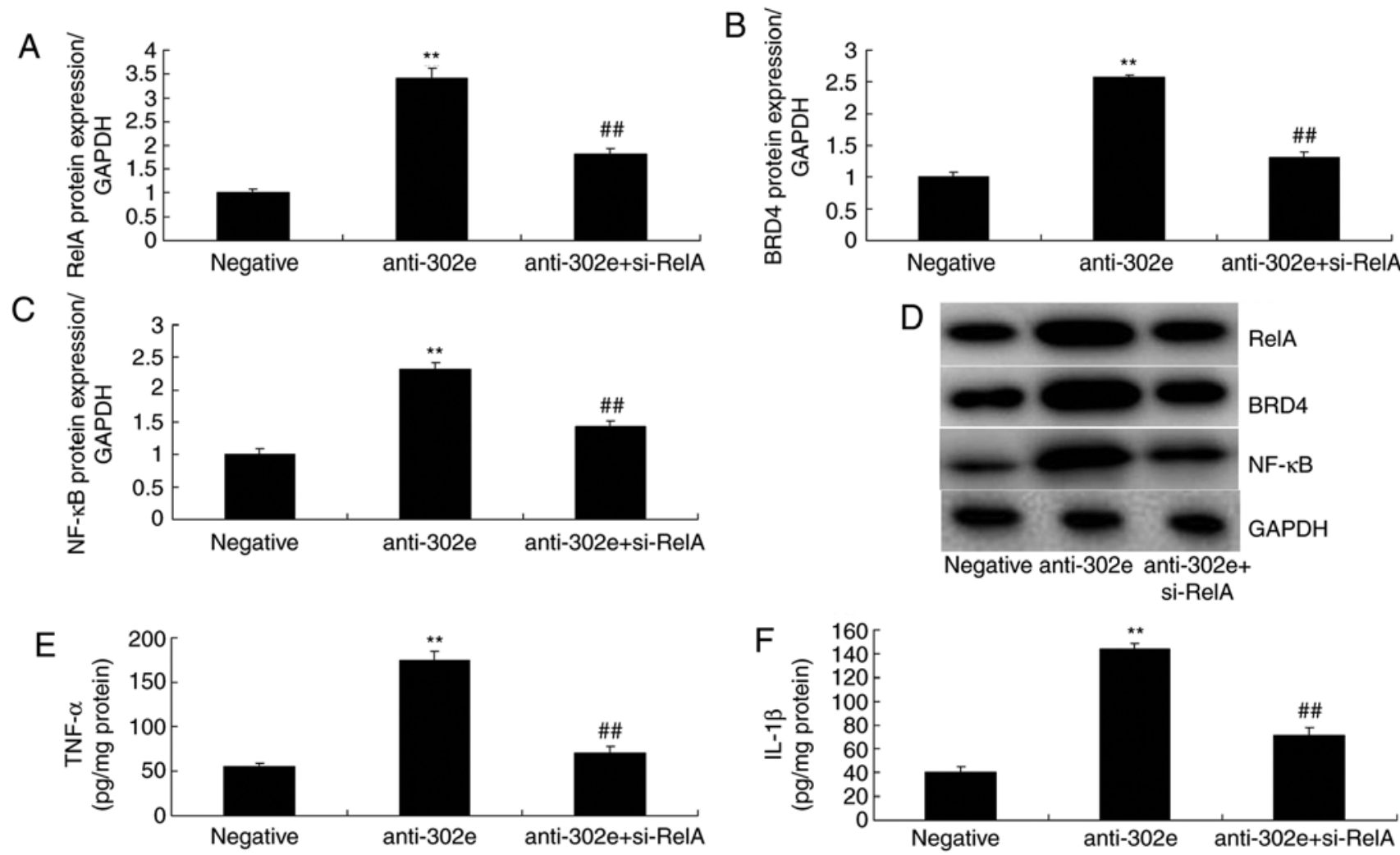

$\mathrm{D}$

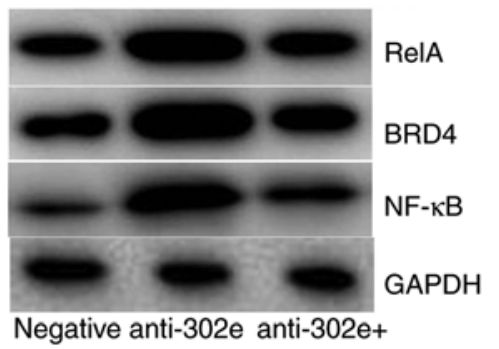

Negative anti-302e anti-302e+
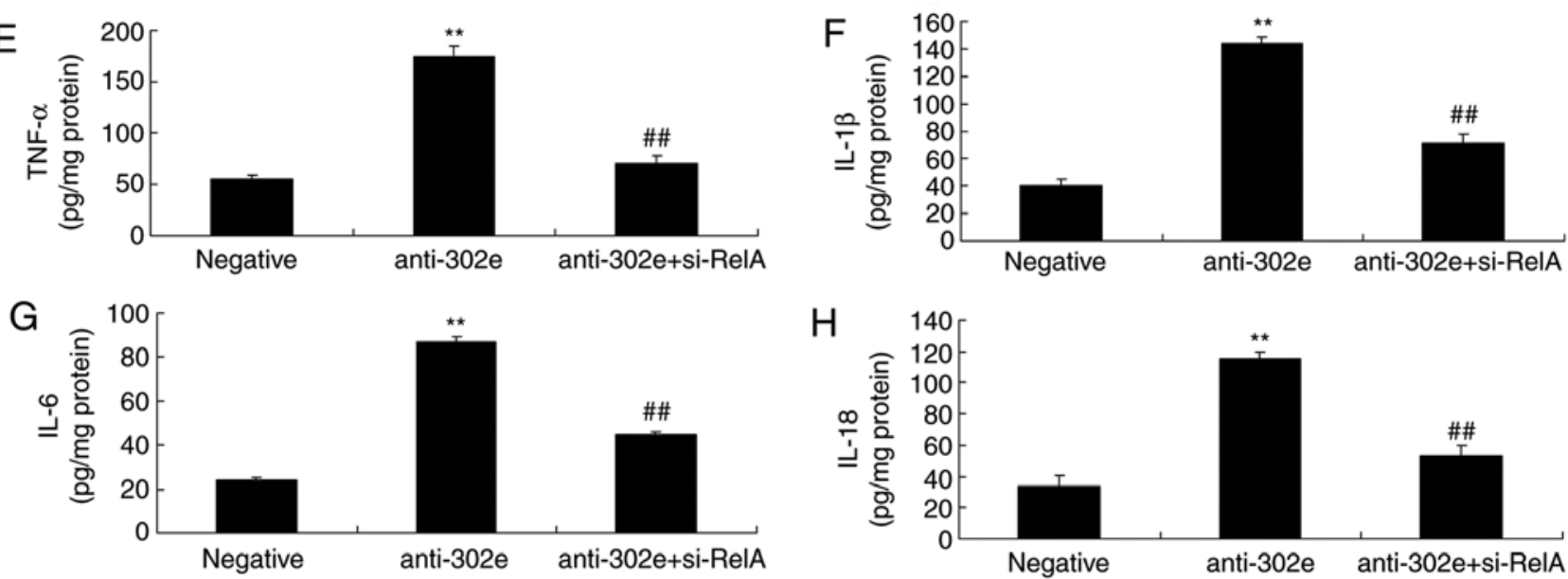

Figure 6. si-RelA reduces the effects of miRNA-302e on inflammation in an in vitro model of infantile pneumonia. (A) RelA, (B) BRD4 and (C) NF- $\mathrm{k}$ protein expression by statistical analysis and (D) western blotting analysis, (E) TNF- $\alpha$, (F) IL-1 $\beta,(\mathrm{G})$ IL-6 and (H) IL-18. ${ }^{* *} \mathrm{P}<0.01$ vs. the negative control group; ${ }^{\# \prime} \mathrm{P}<0.01$ vs. downregulation of miRNA-302e group. Negative, negative control group; anti-302e, downregulation of miRNA-302e group; anti-302e+si-RelA, si-RelA and downregulation of miRNA-302a group; Si, small interfering; IL, interleukin; TNF, tumor necrosis factor; NF, nuclear factor; BRD4, bromodomain-containing protein 4; miRNA, microRNA.

Fig. 5F-I). These results demonstrated that miRNA-302e could decrease inflammation by regulating the RelA/BRD4/NF- $\kappa \mathrm{B}$ signaling pathway in IP in vitro.

si-RelA attenuates the effects of miRNA-302e on inflammation in the in vitro model of IP. To further confirm the role of RelA on the effects of miRNA-302e on inflammation in IP in vitro, si-RelA and 302e inhibitor were transfected in the in vitro model of IP. The activation of RelA, BRD 4 and NF- $\kappa$ B protein expression were suppressed by si-RelA and the downregulation of miRNA-302e in the in vitro model of IP, compared with the downregulation of miRNA-302e group (Fig. 6A-D). The promotion of TNF- $\alpha$, IL-1 $\beta$, IL- 6 and IL-18 levels were also reduced in the in vitro model of IP by downregulation of miRNA-302e in the si-RelA group, in comparison with the miRNA-302e group (Fig. 6E-H).

si-BRD4 attenuates the effects of miRNA-302e on inflammation in an in vitro model of IP. To evaluate the function of BRD4 in the effects of miRNA-302e on inflammation in an in vitro model of IP, si-BRD4 was administered to reduce the protein expression of BRD4 following downregulation of miRNA-302e in an in vitro model of IP, compared with the downregulation of the miRNA-302e group. The induction of BRD4 and NF- $\kappa$ B protein expression were suppressed in the si-BRD4 and downregulation of miRNA-302e group, compared with downregulation of miRNA-302e alone group (Fig. 7A-C). The promotion of TNF- $\alpha$, IL-1 $\beta$, IL-6 and IL-18 levels were also decreased in the in vitro model of IP by downregulation of miRNA-302e and si-BRD4, in comparison with downregulation of miRNA-302e group (Fig. 7D-G).

si-NF- $\kappa B$ attenuates the effects of miRNA-302e on inflammation in an in vitro model of IP. Finally, si-NF- $\kappa \mathrm{B}$ was used to reduce the protein expression of $\mathrm{NF}-\kappa \mathrm{B}$ in an in vitro model of IP following downregulation of miRNA-302e, in comparison with downregulation of miRNA-302e group. The activation of $N F-\kappa B$ protein expression was reduced in the si-NF- $\kappa B$ and downregulation of miRNA-302e group, compared with the 


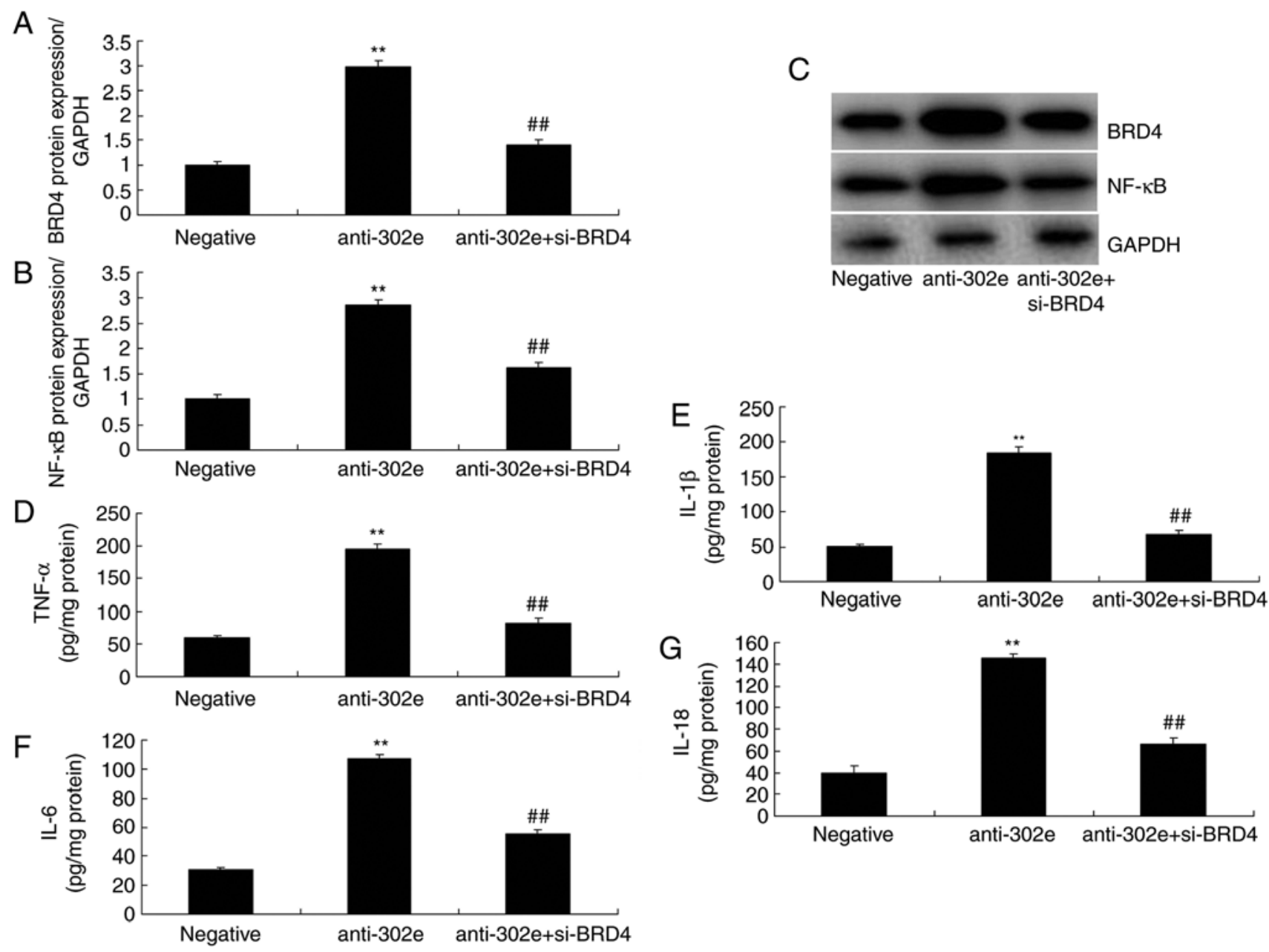

Figure 7. Si-BRD4 reduces the effects of miRNA-302e on inflammation in an in vitro model of infantile pneumonia. (A) BRD4 and (B) NF- $\mathrm{KB}$ protein expression by statistical analysis and (C) western blotting analysis, (D) TNF- $\alpha$, (E) IL-1 $\beta$, (F) IL-6 and (G) IL-18. ${ }^{* *} \mathrm{P}<0.01$ vs. the negative control group; ${ }^{\# \#} \mathrm{P}<0.01 \mathrm{vs}$. the downregulation of miRNA-302e group. Negative, negative control group; anti-302e, downregulation of miRNA-302e group; anti-302e+si-BRD4, Si-BRD4 and downregulation of miRNA-302a group; TNF, tumor necrosis factor; IL, interleukin; NF, nuclear factor; BRD4, bromodomain-containing protein 4; miRNA, microRNA; si, small interfering.

downregulation of miRNA-302e alone group (Fig. 8A-B). The levels of TNF- $\alpha$, IL- $1 \beta$, IL- 6 and IL-18 were reduced in the si-NF- $\kappa \mathrm{B}$ and downregulation of miRNA-302e group, compared with the downregulation of miRNA-302e alone group (Fig. 8C-F). Collectively, these results demonstrated that miRNA-302e may serve a critical role in inflammation IP in vitro.

\section{Discussion}

IP is one of the major pathogens of CAP in children and MPP is suggested to account for $10-40 \%$ of CAP in children (1). IP infection will induce respiratory tract symptoms, but also induce intrapulmonary complications and extrapulmonary systemic impairment, therefore severely reducing the quality of life for the children. An increasing number of studies indicate that immune factors are involved in IP genesis, particularly, certain cytokine levels are abnormal $(19,20)$. miRNAs are a class of non-coding small RNA 18-24 nucleotides in length, which participate in regulating multiple vital processes, including cell proliferation, differentiation and apoptosis (20). A recent study discovered that miRNA serve a vital regulatory role in inflammation; for instance, miR-155, miR-146a, miR-221 and miR-192 are involved in the genesis and development of numerous inflammatory diseases (21). The present study demonstrated that miRNA-302e expression in mice of IP model was reduced, compared with the sham group. Xiao et al (15) and Peng et al (16) demonstrated that the microRNA-302 cluster downregulates enterovirus 71-induced innate immune responses and inflammation. The present study only used one lung adenocarcinoma cell A549 cell and this is insufficient. The authors of the present study plan to use non-cancerous cell line in future studies.

At the acute phase of pneumonia, the action of pathogenic microorganisms and gas exchange area are reduced, which will thereby induce hypoxia and infectious poisoning symptoms to various degrees (22). The non-specific and specific immune functions in the pediatric respiratory tract are poor, the respiratory tract can be easily infected and pulmonary tissue is subjected to inflammation (22). Moreover, cells suffer from degeneration or necrosis, along with inflammatory cell infiltration, which will produce a large amount of reactive oxygen species (ROS) (23). Furthermore, the antioxidant capacity of the lung is insufficient and cannot eliminate these 
A

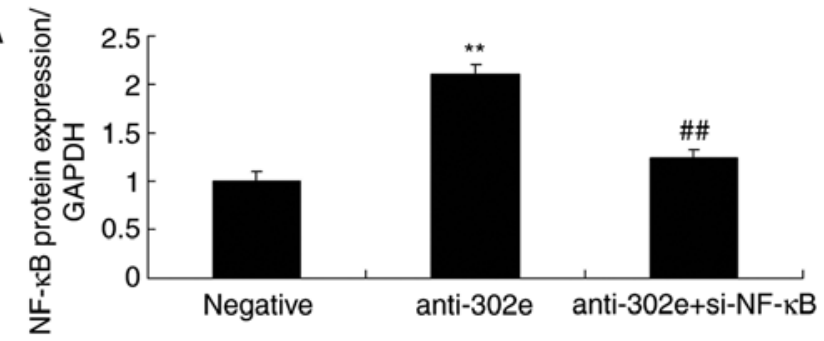

C
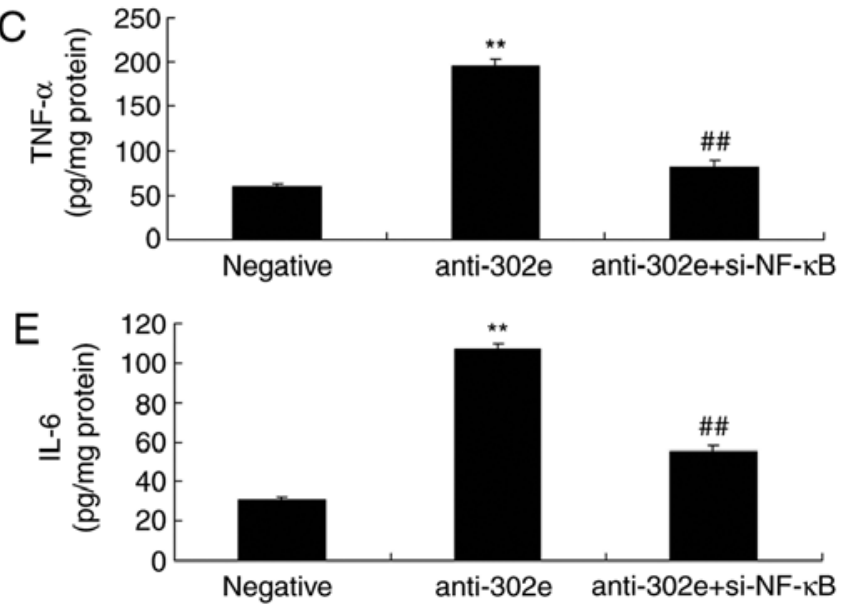

B
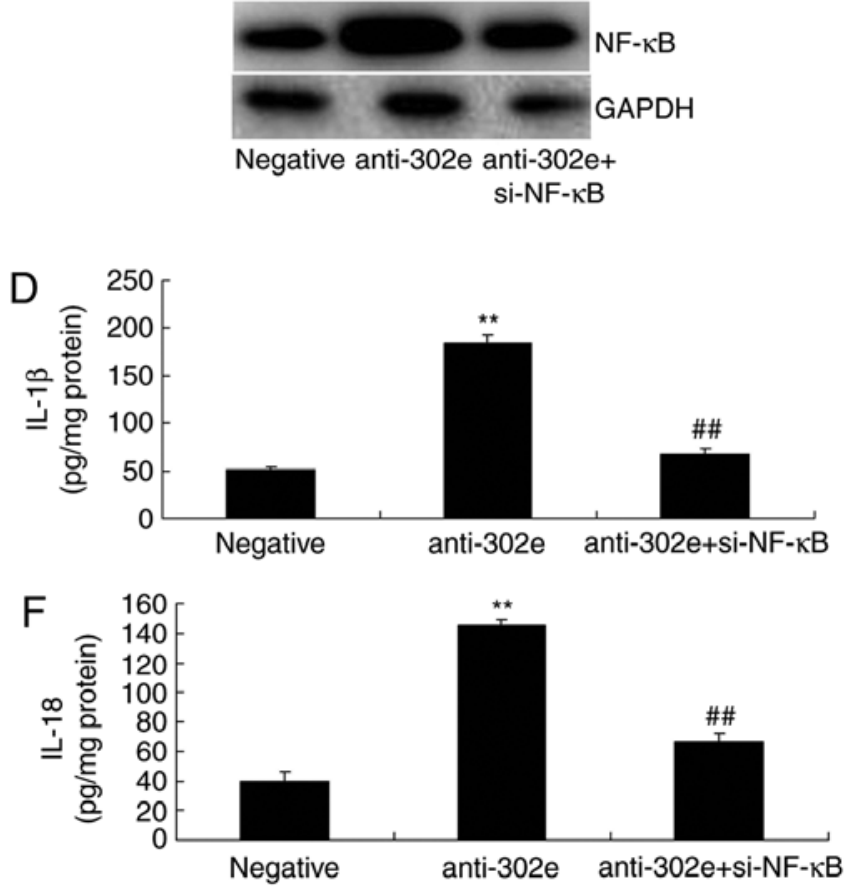

Figure 8. Si-NF- $\kappa$ B reduces the effects of miRNA-302e on inflammation in an in vitro model of infantile pneumonia. (A) NF- $\kappa \mathrm{B}$ protein expression by statistical analysis and (B) western blotting, (C) TNF- $\alpha$, (D) IL-1 $\beta$, (E) IL-6 and (F) IL-18 protein expression. ${ }^{* *} \mathrm{P}<0.01$ vs. downregulation of miRNA-302e group; ${ }^{\# \#} \mathrm{P}<0.01$ vs. downregulation of miRNA-302e group. Negative, negative control group; anti-302e, downregulation of miRNA-302e group; anti-302e+si-NF- $\kappa \mathrm{B}$, si-NF- $\mathrm{B}$ and downregulation of miRNA-302a group; TNF, tumor necrosis factor; IL, interleukin; NF, nuclear factor; BRD4, bromodomain-containing protein 4; miRNA, microRNA.

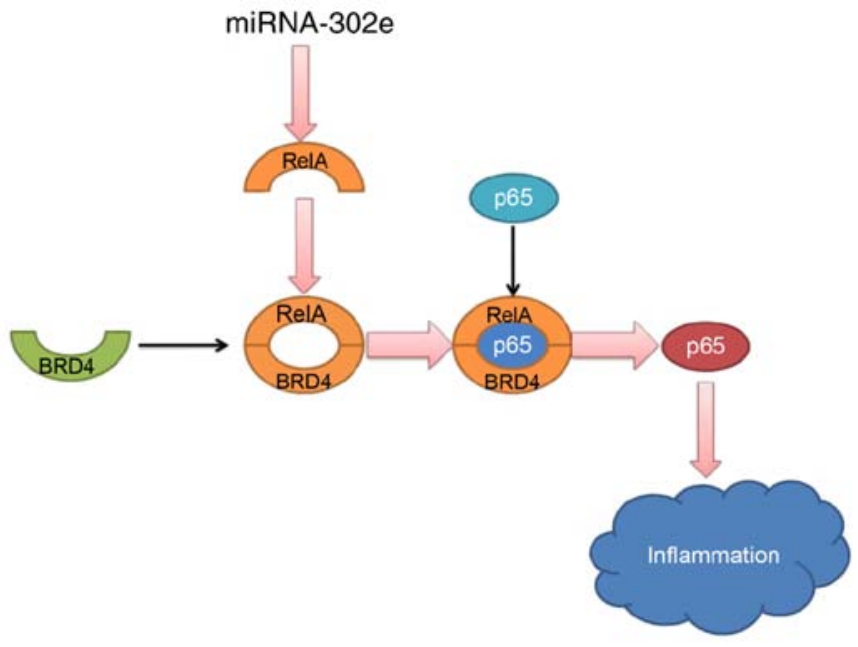

Figure 9. miRNA-302e attenuates inflammation in infantile pneumonia though the RelA signaling pathway. BRD4, bromodomain-containing protein 4; miRNA, microRNA.

ROS in a timely fashion, so a large amount of lipid peroxides will damage the tissue and cell membrane, and increase its permeability, leading to lysosome rupture and tissue necrosis. Therefore, it will affect the lung function. Therefore, how to rapidly and accurately diagnose IP at acute phase is of vital significance to the treatment and rehabilitation of children. In this study, it was demonstrated that downregulation of miRNA-302e promoted TNF- $\alpha$, IL-1 $\beta$, IL- 6 and IL-18 levels in vitro model of IP. Xiao et al (15) demonstrated that
miRNA-302e attenuates allergic inflammation in vitro model by targeting RelA/NF- $\kappa \mathrm{B}$ activation.

Multiple intracellular regulatory factors can activate transcription, therefore resulting in reduced apoptosis and enhanced proliferation (24). Therefore, it is regarded as an important link during the genesis and development of gastric cancer. NF- $\mathrm{NB}$ is one of these factors, which can regulate expression of multiple genes and is closely associated with tumor genesis and development (25). RelA(p65) is one of the $\mathrm{NF}-\kappa \mathrm{B}(\mathrm{Rel})$ family members. In the absence of signal stimulation, the inactive RelA can bind with inhibitor (I) $\kappa \mathrm{B}$ and exist in cytoplasm in the form of a complex. In contrast, $\mathrm{I} \kappa \mathrm{B}$ will be phosphorylated by the I $\mathrm{B}$ kinase complex in the presence of a foreign stimulation signal (13). Therefore, the RelA/IkB complex will be activated and isolated, and the free RelA will enter the nucleus to regulate associated gene expression. The present study demonstrated that downregulation of miRNA-302e induced RelA, BRD4 and NF- $\kappa$ B protein expression in the in vitro model of IP. Si-RelA, si-BRD4 or si-NF- $\kappa$ B reduced the effects of miRNA-302e on inflammation in the in vitro model of IP. Xiao et al (15) demonstrated that miRNA-302e attenuates allergic inflammation in an in vitro model by targeting RelA/NF- $\mathrm{B}$ activation.

In conclusion, the present study demonstrates that miRNA-302e expression in mice IP models was reduced. miRNA-302e attenuates inflammation in IP though the RelA/BRD4/NF- $\kappa$ B signaling pathway (Fig. 9). These results reveal a novel anti-inflammatory role of miRNA-302e in activated mast cells, suggesting that miR-302e may be a promising therapeutic target for the treatment of IP. 


\section{Acknowledgements}

Not applicable.

\section{Funding}

No funding was received.

\section{Availability of data and materials}

The analyzed data sets generated during the present study are available from the corresponding author on reasonable request.

\section{Authors' contributions}

SL designed the experiments. QS, YZ, JL and WC performed the experiments. SL analyzed the data. SL wrote the manuscript. All authors read and approved the final manuscript.

\section{Ethics approval and consent to participate}

All experiments have been approved by the Ethics Committee of The People's Hospital of Dongying (Dongying, China).

\section{Patient consent for publication}

Not applicable.

\section{Competing interests}

The authors declare that they have no competing interests.

\section{References}

1. Launay E, Levieux K, Levy C, Dubos F, Martinot A, Vrignaud B Lepage F, Cohen R, Grimprel E, Hanf M, et al: Compliance with the current recommendations for prescribing antibiotics for paediatric community-acquired pneumonia is improving: Data from a prospective study in a French network. BMC Pediatr 16: 126, 2016

2. Bai D, Han A and Cong S: The effect of down-regulation of CCL5 on lipopolysaccharide-induced WI-38 fibroblast injury: A potential role for infantile pneumonia. Iran J Basic Med Sci 21 449-454, 2018.

3. Cho BO, Yin HH, Park SH, Byun EB, Ha HY and Jang SI: Anti-inflammatory activity of myricetin from Diospyros lotus through suppression of NF- $\kappa \mathrm{B}$ and STAT1 activation and Nrf2-mediated HO-1 induction in lipopolysaccharide-stimulated RAW264.7 macrophages. Biosci Biotechnol Biochem 80 $1520-1530,2016$

4. Rocha GR, Florez Salamanca EJ, de Barros AL, Lobo CIV and Klein MI: Effect of tt-farnesol and myricetin on in vitro biofilm formed by Streptococcus mutans and Candida albicans. BMC Complement Altern Med 18: 61, 2018.

5. Revised American Society for Reproductive Medicine classification of endometriosis: 1996. Fertil Steril 67: 817-821, 1997.

6. Kim GD: Myricetin inhibits angiogenesis by inducing apoptosis and suppressing PI3K/Akt/mTOR signaling in endothelial cells J Cancer Prev 22: 219-227, 2017.

7. Zukauskas A, Mrsny RJ, Cortés Barrantes P, Turner JR, Leong JM and McCormick BA: Transporters MRP1 and MRP2 regulate opposing inflammatory signals to control transepithelial neutrophil migration during streptococcus pneumoniae lung infection. mSphere 3, 2018.

8. Berg AS, Inchley CS, Fjaerli HO, Leegaard TM, Lindbaek M and Nakstad B: Clinical features and inflammatory markers in pediatric pneumonia: A prospective study. Eur J Pediatr 176: 629-638, 2017.
9. Dai JP, Wang QW, Su Y, Gu LM, Zhao Y, Chen XX, Chen C, Li WZ, Wang GF and Li KS: Emodin inhibition of influenza A virus replication and influenza viral pneumonia via the $\mathrm{Nrf} 2$, TLR4, p38/JNK and NF-kappaB pathways. Molecules 22, 2017.

10. Ying H, Kang Y, Zhang H, Zhao D, Xia J, Lu Z, Wang H, Xu F and Shi L: MiR-127 modulates macrophage polarization and promotes lung inflammation and injury by activating the JNK pathway. J Immunol 194: 1239-1251, 2015.

11. Fei S, Cao L and Pan L: microRNA3941 targets IGF2 to control LPS-induced acute pneumonia in A549 cells. Mol Med Rep 17: 4019-4026, 2018.

12. Wang W, Chen M, Jin X, Li X, Yang Z, Lin H and Xu S: $\mathrm{H}_{2} \mathrm{~S}$ induces Th1/Th2 imbalance with triggered $N F-\kappa B$ pathway to exacerbate LPS-induce chicken pneumonia response. Chemosphere 208: 241-246, 2018.

13. Peng C, Han J, Ye X and Zhang X: IL-33 treatment attenuates the systemic inflammation reaction in acinetobacter baumannii pneumonia by suppressing TLR4/NF- $\mathrm{KB}$ signaling. Inflammation 41 : 870-877, 2018

14. Li D, Beisswenger C, Herr C, Hellberg J, Han G, Zakharkina T, Voss M, Wiewrodt R, Bohle RM, Menger MD, et al: Myeloid cell RelA/p65 promotes lung cancer proliferation through Wnt $/ \beta$-catenin signaling in murine and human tumor cells. Oncogene 33: 1239-1248, 2014

15. Xiao L, Jiang L, Hu Q and Li Y: MiR-302e attenuates allergic inflammation in vitro model by targeting RelA. Biosci Rep 38 , 2018.

16. Peng N, Yang X, Zhu C, Zhou L, Yu H, Li M, Lin Y, Wang X, Li Q, She Y, et al: MicroRNA-302 cluster downregulates enterovirus 71-induced innate immune response by targeting KPNA2. J Immunol 201: 145-156, 2018.

17. Yamamoto Y,Hosoda K, Imahori T, Tanaka J, Matsuo K, Nakai T, Irino Y, Shinohara M, Sato N, Sasayama T, et al: Pentose phosphate pathway activation via HSP27 phosphorylation by ATM kinase: A putative endogenous antioxidant defense mechanism during cerebral ischemia-reperfusion. Brain Res 1687: 82-94, 2018.

18. Xia N, Chen G, Liu M, Ye X, Pan Y, Ge J, Mao Y, Wang H, Wang $\mathrm{J}$ and $\mathrm{Xie} \mathrm{S}$ : Anti-inflammatory effects of luteolin on experimental autoimmune thyroiditis in mice. Exp Ther Med 12: 4049-4054, 2016.

19. Lee da $\mathrm{H}$ and Lee CS: Flavonoid myricetin inhibits TNF- $\alpha$-stimulated production of inflammatory mediators by suppressing the Akt, mTOR and NF- $\kappa \mathrm{B}$ pathways in human keratinocytes. Eur J Pharmacol 784: 164-172, 2016.

20. Shamir R and Garty BZ: Pneumocystis carinii pneumonia associated with adrenocorticotropic hormone treatment for infantile spasms. Eur J Pediatr 151: 867, 1992.

21. Liu M, Han T, Shi S and Chen E: Long noncoding RNA HAGLROS regulates cell apoptosis and autophagy in lipopolysaccharides-induced WI-38 cells via modulating miR-100/NF- $\kappa \mathrm{B}$ axis. Biochem Biophys Res Commun 500: 589-596, 2018.

22. Yu B, Shen Y, Qiao J and Cui Q: Geniposide attenuates Staphylococcus aureus-induced pneumonia in mice by inhibiting NF- $\kappa$ B activation. Microb Pathog 112: 117-121, 2017.

23. Roade Tato L, Burgos Cibrian J, Curran Fábregas A, Navarro Mercadé J, Willekens R, Martín Gómez MT, Ribera Pascuet E and Falcó Ferrer V: Immune reconstitution inflammatory syndrome in HIV-infected patients with Pneumocystis jirovecii pneumonia. Enferm Infecc Microbiol Clin 36: 621-626, 2017 (In English, Spanish).

24. Song C, He L, Zhang J, Ma H, Yuan X, Hu G, Tao L, Zhang J and Meng J: Fluorofenidone attenuates pulmonary inflammation and fibrosis via inhibiting the activation of NALP3 inflammasome

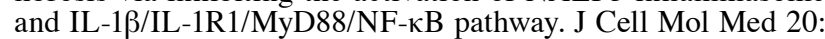
2064-2077, 2016.

25. Wu H, Zhao G, Jiang K, Chen X, Zhu Z, Qiu C, Li C and Deng G: Plantamajoside ameliorates lipopolysaccharide-induced acute lung injury via suppressing NF- $\mathrm{KB}$ and MAPK activation. Int Immunopharmacol 35: 315-322, 2016.

This work is licensed under a Creative Commons Attribution-NonCommercial-NoDerivatives 4.0 International (CC BY-NC-ND 4.0) License. 